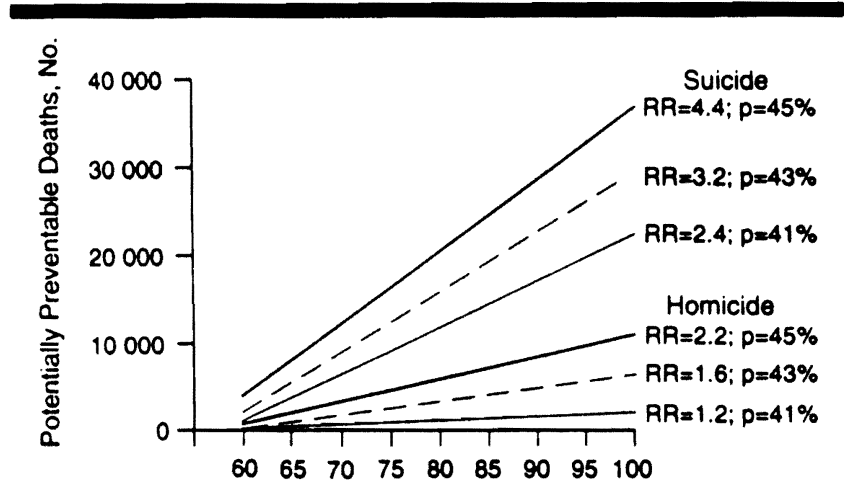

Prevalence of Homes Without Guns, \%

Potentially preventable homicides and suicides by prevalence of homes without guns. United States. 1988 through 1990. RR indicates unadjusted risk of homicide or suicide from guns in home; and $p$, baseline prevalence of homes with guns.

effort to kill. Also, there is no evidence of compensatory increases in homicides involving other weapons when societal firearm access is restricted.

Case fatality rates for suicides attempted with a gun are much higher than for suicides attempted otherwise. ${ }^{5}$ Crossnational evidence suggests that where the favored means of committing suicide is removed there is a decrease in suicide. ${ }^{5}$ Given that guns are the favored means of committing suicide in the United States, some people may be less likely to choose other means if denied firearm access. Suicidal people are typically ambivalent about taking their lives, and the period at risk may be fleeting. Cook's view reflects our own: "The argument here is not that the availability of lethal means is the sole determinant of suicide rates but, rather, that the availability of lethal means influences the extent to which suicidal impulses are translated into complete suicides."

The limitations of our approach include using risk estimates $^{1,2}$ that may not accurately reflect the population's risk and not adjusting for all confounding factors (note that the adjusted risk estimates of both case-control studies were higher than the unadjusted estimates ${ }^{1,2}$ ).

It would appear that decreasing the prevalence of guns in the home could be an important part of a national strategy to prevent homicide and suicide.
Jeffrey J. Sacks, MD, MPH
James A. Mercy, PhD
George W. Ryan, PhD
R. Gibson Parrish, MD
Centers for Disease Control and Prevention
Atlanta, $\mathrm{Ga}$

1. Kellermann AL, Rivara FP, Rushforth NB, et al. Gun ownership as a risk factor for homicide in the home. $N$ Engl J Med. 1993;329:1084-1091.

2. Kellermann AL, Rivara FP. Somes G, et al. Suicide in the home in relation to gun ownership. N Engl J Med. 1992;327:467-472.

3. Davis JA, Smith TW. Genoral Social Survoys, 1978-1991: Cumulative Codebook. Chicago, Ill: National Data Program for the Social Science Series No. 12, National Opinion Research Center; 1991:989.

4. Saltzman LE, Mercy JA, O'Carroll PW, Rosenberg ML, Rhodes PH. Weapon involvement and injury outcomes in family and intimate asasults. JAMA. 1992;267: 3043-3047.

5. Cook PJ. The technology of personal violence. In: Tonry M, ed. Crime and Jus. tice: A Reviow of Research. Chicago, 1ll: University of Chicago Prese; 1991;14:1-72.

\section{The Distribution of Organs for Liver Transplantation}

To the Editor.-The article by Dr Bronsther and colleagues ${ }^{1}$ contained serious inaccuracies and misleading statements.

The first national liver allocation protocol adopted by the United Network for Organ Sharing (UNOS) was based on a system recommended by one of the authors of the article by Bronsther et al. A preexisting, voluntary organ sharing sys-

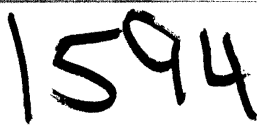

Approved Liver Transplant Programs*

\begin{tabular}{cccc}
\hline Year & $\begin{array}{c}\text { Liver } \\
\text { Pransplant } \\
\text { Programs }\end{array}$ & $\begin{array}{c}\text { Annual } \\
\text { Not Increase }\end{array}$ & $\begin{array}{c}\text { Annual } \\
\text { Increase, \% }\end{array}$ \\
\hline 1987 & 58 & $\ldots$ & $\ldots$ \\
\hline 1888 & 66 & 8 & 13.8 \\
\hline 1989 & 79 & 13 & 19.7 \\
\hline 1990 & 85 & 6 & 7.6 \\
\hline 1991 & 93 & 8 & 9.4 \\
\hline 1992 & 105 & 12 & 12.9 \\
\hline 1993 & 112 & 7 & 6.7 \\
\hline
\end{tabular}

- Table shows the cumulative number of approved liver transplant programs at year's end for the years shown and the percentage increase in the number of programs from year to year.

tem calied UNOSSTAT was continued on a voluntary basis for the sickest patients. It permitted organ procurement organizations to override the national allocation system and distribute livers to UNOS STAT patients from the national pool of waiting patients before considering patients listed on local, regional, and national waiting lists who ranked higher than the UNOS STAT patients for receipt of these organs.

Bronsther et al incorrectly assert that allocation tended to be autoregulatory when the UNOS STAT classification was in place. To the contrary, by October 1989 the transplant community began to question the merits of UNOS STAT, because of the ease with which it could be (and the degree to which it was believed to be) abused and because it was directing too many organs to the sickest patients to the overall detriment of potential liver recipients in general.

The decision to eliminate the UNOS STAT category and substitute a more defined and monitorable classification for the most medically urgent category of patients (implemented in January 1991) was endorsed by the UNOS Ethics Committee and supported overwhelmingly by the rest of the transplant community, including the UNOS Patient Affairs Committee. The only negative public comments received by UNOS on this change came from institutions or individuals affiliated with the transplant center of Bronsther et al and largely concentrated on issues other than the elimination of UNOS STAT, per se.

Bronsther et al suggest that following the elimination of UNOS STAT, transplant centers-other than the center with which the authors are associated-would fail to provide transplants for the most critical liver patients, a "stampede" of new transplant centers would be started to take advantage of the "organ-rich regions," and organs available for transplantation would docrease in number. In truth, from 1992 to 1993 a total of 1479 iver transplant recipients $(22.7 \%$ of all liver transplants during this period) were in the most critically urgent status code at the time of their transplant (UNOS OPTN [Organ Procurement and Transplantation Network] data as of January 23, 1994). There has been no unusual increase in the number of liver transplant programs approved after January 1,1991 , compared with before January 1,1991 , as shown in the Table (UNOS membership data as of February 4, 1994). Finally, the number of cadaveric organ donors in 1993 increased by $7 \%$ over the number of (cadaveric) donors in 1992.

Until we have enough organs for every waiting patient, any organ allocation policy will appear unfair to someone. All national organ allocation policies involve difficult and controversial decisions. The system is continuously undergoing thoughtful and honest reevaluation. Distortions of facts relevant to this profound problem do not advance the process.

Douglas J. Norman, MD

United Network for Organ Sharing

Portland, Ore

1. Bronsther O, Fung JJ, Tzakis A, Van Thiel D, Starzd TE. Prioritization and organ distribution for liver transplantation. JAMA. 1994:271:140-143. 
To the Editor.-I was disturbed by the article by Dr Bronsther and colleagues ${ }^{\prime}$ regarding the prioritization of livers for transplantation. Rather than manufacture a rationale to justify their claim to a greater share of the limited pool of donor livers, the authors would better serve the transplant community by addressing the donor shortage. Alexander and Vaughn ${ }^{2}$ showed that $25 \%$ of the patients awaiting transplantation died because of the lack of a donor liver. Any discussion of liver distribution must be tempered by the fact that there are too few livers available for all potential recipients, and even if all transplants were carried out at one center, there would still be a substantial mortality rate for patients on the waiting list. As long as the number of potential recipients exceeds the supply of donor livers, any revision of the present allocation system would accomplish nothing more than changing the ZIP code of the patients who die awaiting transplantation.

The present liver allocation system uses medical urgency as the primary determinant, but expands the potential recipient's choices by allowing most patients to undergo transplantation at a local or regional center rather than be displaced far from home. These new centers are not automatically inferior to established centers, and it is unconscionable to suggest that these centers are wasting livers and having patients receive transplants unnecessarily. All programs performing transplants must be approved by UNOS and are subject to the same regulations.

The liver transplantation community is suffering from a maldistribution of recipients, not donors. This is clearly shown by the Veterans Affairs' (VA) system for liver transplantation. ${ }^{3}$ Referral of all potential liver recipients in the VA system to a single center maldistributes recipients rather than donors. Local and regional patients are forced to compete with VA patients who add nothing to the local donor pool. It would be more equitable to offer liver transplantation through the VA systems across the country.

Finally, in Pittsburgh magazine, the Transplant Institute in Pittsburgh, $\mathrm{Pa}$, was described as "financially self-sufficient with an annual budget of $\$ 200$ million dollars generated primarily from patient fees $(75 \%$ to $85 \%$ were from outside the region)." Obviously, any change in liver distribution that decreases the ability of a center to perform transp ar.ts at the same rate will decrease an institution's income. I hope that the business aspect of liver transplantation is not the driving force in attempts to change the allocation system.

In view of the discrepancy between the donor liver supply and the number of potential recipients, a daily triage is occurring. While the authors confirm that a limited number of critically ill patients can be salvaged with transplants, I remain unconvinced that the ill-defined concept of "medical urgency" requires a shift back to a national distribution system.

Expanding the donor pool is the only way substantially to reduce the mortality rates for patients on the waiting list for liver transplantation.

\section{R. Patrick Wood, MD \\ Houston, Tex}

1. Bronsther O, Fung JJ, Tzakis A, Van Thiel D, Starzl TE. Prioritization and organ distribution for liver transplantation. JAMA. 1994:271:140-143.

2. Alexunder JW, Vaughn WK. The use of manginal donors for organ transplanta2. Alexunder JW, Vaughn WK. The Use
tion. Transplantation. 1991:51:135.141.

tion. Transplantation. 1991:51:135-141.
3. Evans RW, Manninen DL, Dong FB, et al. An economic analysis of liver transplantation: costs, insurance coverage, and reimbursement. In: Evans $R W$, Manninen DL, Dong FB. The National Cooperative Tranoplantation Study: Final Report. So attle, Wash: Battelle-Seattle Research Center, June 1991.

4. Pilecki M. Pittsburgher of the year: Staral's trek. Pittsburgh. January 1994:39-44.

In Reply.-It is true that one of the authors (T.E.S.) endorsed the original organ distribution plans and in fact wrote them in May 1987 in order to prevent a UNOS default of contract obligation. One plan was for kidneys and the other for extrarenal organs. Disputes within the appointed 0.zen distri- bution committee had prevented development of the required document. What was used was taken verbatim from two impending publications describing the distribution systems already in place in Pittsburgh. ${ }^{12}$ The existence of these manuscripts had been made known to UNOS by two colleagues, resulting in the last-minute recruitment of Dr Starzl.

The principles of both plans are still embraced by UNOS, but with a changed meaning. Originally, overwhelming weight for liver distribution was given to urgency of need because there is no treatment option comparable with the artificial kidney. "Boutique" liver recipients called in for operation from the 19th hole of the golf course have a $90 \%$ survival, but relative risk analyses of the case material summarized by Bronsther et al suggest that they could have had an even higher survival without transplant intervention. ${ }^{3}$ The appropriate timing of liver transplantation is everything, and requires a national donor pool from which the recipient population can be served, as called for by the Gore bill of 1985 . After 1987 the United States was carved up into regions among which organ movement is discouraged if not prohibited. During this time, UNOS committees voted that a national list was not feasible in spite of irrefutable scientific evidence to the contrary.

When UNOS also used the Pittsburgh kidney allocation system for its contract proposal in 1987, it was understood clearly that only the rare perfect HLA match conferred a survival advantage, and even then a surprisingly small one. Yet this nonpredictive test was adopted in increments by UNOS as the dominant factor in kidney distribution. Waiting in line lost its value, kidneys sprouted wings en route to distant places, and a UNOS committee claimed that a single national list would be impractical, even as one was imposed for dissemination of "matched kidneys." The racial bias directed against minorities became a national shame."

The Pittsburgh program is a founder and the single most active member of UNOS. We do not aspire to a governance role for the very reason implied by $\mathrm{Dr}$ Wood. The problems with UNOS are not with its network of skilled and devoted staff and procurement officers, but with the committees and governance process cited by both correspondents to support their statements. Embedded into this structure are business and professional conflicts of interest that are defended with the rhetoric of "justice" and "utility," terms used to replace the easily understood word "fairness." As soon as this is more generally perceived, the lines of authority will pass to the patients for whose benefit UNOS exists. Patients can then go to where they choose, not to where they are driven.

Oscar Bronsther, MD

John J. Fung, MD, PhD

Andreas Tzakis, MD

Thomas E. Starzl, MD, PhD

University of Pittsburgh

Pittsburgh, $\mathrm{Pa}$

David Van Thiel, MD

Oklahoma Transplantation Institute

Oklahoma City

1. Stard TE, Hakala T, Tzakis A, et al. A multifactorial system for equitable selec tion of cadaveric kidney recipients. JAMA. 1987;257:3073-3075.

2. Starzl TE, Gordon RD, Tzakis A, et al. Equitable allocation of extrarenal organs: with special reference to the liver. Transplant Proc. 1988;20:131-138.

3. Eghteasd B. Bronsther O, Irish W, et al. Disease gravity and urgency of need a 3. Eghteas B, Bronsther O, Irish W, et al. Disease g

guidelines for liver allocation. Hepatology. In press. tation. JAMA. 1993;270:1352-1356.

\section{State Plans for Surrogate Decision Making}

To the Editor.-The recent Law and Medicine article' described the New York State Surrogate Decision-Making Committee program. A State Substitute Medical Decision-Mak- 